\title{
Plasma concentration monitoring of aminoglycosides
}

\author{
F. Follath, M. Wenk and S. Vozeh
}

\section{Division of Clinical Pharmacology, Medical Department of the University, Kantonsspital Basle, Switzerland}

\begin{abstract}
A narrow therapeutic margin and poor predictability of plasma concentrations are the main reasons for drug level monitoring during aminoglycoside treatment. Gentamicin, tobramycin, amikacin and netilmicin can now be accurately and rapidly measured by radioenzymic, radio-immuno and enzyme-immuno assays. Routine determinations of peak ( $1-2 \mathrm{~h}$ post dose) and trough levels are recommended to ensure adequate dosage in all patients with serious Gram-negative infections, especially when renal function is impaired. It should be realized, however, that maintaining aminoglycoside concentrations within a given range will only reduce, but not entirely eliminate the risk of toxicity. The pharmacokinetic behaviour of these antibiotics leads to a progressive drug accumulation in renal tissue and the inner ear, which depends both on dosage amd duration of treatment.
\end{abstract}

\begin{abstract}
Une marge thérapeutique étroite ainsi que la difficulté à prédire les concentration plasmatiques, sont les principales raisons de contrôle des taux sanguins au cours d'un traitement par les aminoglycosides. Aujourd'hui les concentrations de gentamicine, tobramycine, amikacine et nétilmicine peuvent être mesurées rapidement et de manière précise par les méthodes radio-enzymatiques, radioimmunologiques et enzymo-immunologiques. La détermination du pic (l à 2 heures après administration) et du taux résiduel est recommandée pour assurer un dosage adéquat chez tous les malades atteints d'une infection sevère à germes Gram-négatif, et particulièrement en cas d'insuffisance rénale. Il faut pourtant bien garder à l'esprit, que le fait de maintenir la concentration d'une aminoglycoside à un niveau donné, permet seulement de diminuer les risques de toxicité, mais pas de les éliminer totalement. La pharmacocinétique particulière de ces antibiotiques entraine une accumulation progressive dans le parenchyme rénal et dans l'oreille interne, qui dépend à la fois de la posologie et de la durée du traitement.
\end{abstract}

Monitoring of serum drug levels is often recommended to guide the dosage of aminoglycosides, especially in patients with reduced renal function. Despite the widespread use of these antibiotics, such measurements are only practised in a few specialized laboratories. However, recent progress has resulted in more rapid, simple and specific assays that would potentially allow routine determination of 
gentamicin, tobramycin, amikacin and netilmicin in most hospitals. Before advocating this policy, a critical reassessment of the practical value of aminoglycoside monitoring is necessary to justify the demands for additional manpower and equipment. Does the knowledge of plasma concentrations really increase the effectiveness and safety of aminoglycoside treatment?

\section{Rationale of drug level monitoring}

For any drug, plasma concentration measurements are meaningful only if the following basic requirements are fulfilled:

(1) the difference between therapeutic and toxic doses is small (narrow therapeutic margin);

(2) plasma concentrations on standardized dosage are highly variable;

(3) a direct relationship can be shown to exist between drug levels and therapeutic or toxic effects.

Some of these reasons are relevant to the measuring of aminoglycoside serum levels. In spite of careful adaptation of antibiotic dosage, damage to the kidney or eighth nerve cannot be entirely avoided with any of the available agents. An advantage of tobramycin over gentamicin with respect to nephrotoxicity (Smith et al., 1980), and of netilmicin over amikacin for ototoxicity (Barza et al., 1980) has been reported, but a 12-15\% incidence of side-effects still occurred even with the 'better tolerated' drugs. Although the risk of aminoglycoside treatment is probably much lower in patients with less severe infections, the narrow margin of safety remains a cause for continuing concern.

A further well-known problem of aminoglycoside treatment is the poor predictability of serum levels (Barza \& Lauermann, 1978). Wide variations can be observed, especially, when prescribing is based only on the clinical judgement of physicians (Mawer et al., 1974). Various dosing aids have therefore been developed that include age, sex, body weight, serum creatinine or creatinine clearance, to estimate optimum dose requirements. Special computer-derived guidelines were shown to achieve a statistically significant correlation between predicted and measured concentrations of gentamicin (Hull \& Sarubbi, 1976) or amikacin (Sarubbi \& Hull, 1978) obtained in patients. However, in individual cases even with these nomograms up to $100 \%$ differences may occur between the target and plasma levels actually achieved.

The third reason for monitoring, that is the demonstration of adequate serum concentrations, is more controversial than generally assumed. Optimum ranges of peak concentrations of 5-10 mg/ 1 are usually cited for gentamicin or tobramycin and $20-30 \mathrm{mg} / \mathrm{l}$ for amikacin, but hard data to substantiate these values are difficult to find. It appears logical that peak serum concentrations should be higher than the minimum inhibitory concentration of the micro-organism causing the infection. However, it is not known how much higher and during what fraction of the dosing interval the bactericidal levels should be maintained.

No uniform views exist about toxic serum concentrations. As shown in Table I, different authors have reached quite dissimilar conclusions in trying to decide whether peak or trough are more relevant. All possible combinations of negative or positive answers have been found. The discrepancies with regard to tolerable $C_{\max }$ 
Table I. Relation between plasma levels and toxicity of aminoglycosides

\begin{tabular}{|c|c|c|c|c|c|}
\hline \multirow{2}{*}{ Author } & \multirow{2}{*}{ Drug } & \multicolumn{2}{|c|}{ Nephrotoxicity } & \multicolumn{2}{|c|}{ Ototoxicity } \\
\hline & & $C_{\max }$ & $C_{\min }$ & $C_{\max }$ & $C_{\min }$ \\
\hline Dahlgren, Anderson \& Hewitt (1975) & \multirow{6}{*}{$\left.\begin{array}{l}\text { Gentamicin } \\
\text { Amikacin } \\
\text { Gentamicin } \\
\text { Amikacin } \\
\text { Gentamicin } \\
\text { Gentamicin } \\
\text { Amikacin } \\
\text { Netilmicin }\end{array}\right\}$} & no & yes & - & - \\
\hline Black et al. (1976) & & - & - & yes & yes \\
\hline Smith et al. (1978) & & yes & yes & - & - \\
\hline Schentag et al. (1978) & & - & yes & - & - \\
\hline Gailiunas et al. (1978) & & - & - & no & no \\
\hline Bock, Edelstein \& Meyer (1980) & & yes & no & yes & yes \\
\hline
\end{tabular}

values may be explained by differences in the mode of drug administration and the timing of blood samples, since during the early distribution phase great concentration changes occur within a short time. To study the influence of peak levels on toxicity a standardization of blood sampling would be necessary. Such obvious reasons cannot be the only explanation of the contradictory findings about the role of trough levels.

Are there other factors, such as total dose and duration of treatment, that also influence aminoglycoside toxicity? The data of Mawer et al. (1974), Black et al. (1976), Gailiunas et al. (1978) and Bock, Edelstein \& Meyer (1980) indicate an increased risk of ototoxicity with prolonged treatment and higher cumulative dosage. Current knowledge of the pharmacokinetic behaviour of this antibiotic group supports the assumption that drug accumulation in the organ is an important cause of toxicity. Contrary to earlier views on the elimination of aminoglycosides, a slow terminal excretion phase is present not only after gentamicin or tobramycin but also with netilmicin (Wenk et al., 1979), sissomicin (Follath et al., 1978) and amikacin (Wenk \& Follath, 1980). As a consequence, on repetitive dosing drug concentrations will increase progressively in certain tissues, even though serum levels are maintained within a recommended range. Prediction of drug levels in the body from a multicompartment kinetic model was remarkably accurate in the patients of Schentag et al., (1977). We therefore propose to consider not only peak or trough serum concentration, but also the area under the serum concentration curve during a dosing interval as a parameter relevant to toxicity. By computer simulations it can be shown that the area under the curve correlates directly with drug amounts in the peripheral tissue compartment (Figure 1). A dosing regimen producing a greater area is therefore more likely to result in stronger aminoglycoside accumulation. The values of the area under the cuvre can be easily approximated graphically if two serum concentrations during a dosing interval are available (Figure 2). Further studies will be required to evaluate the clinical usefulness of this criterion.

\section{Methods for measuring aminoglycoside levels}

If it is accepted that serum concentration measurements are clinically helpful, we have to use appropriate methods to obtain reliable results rapidly. Among the 


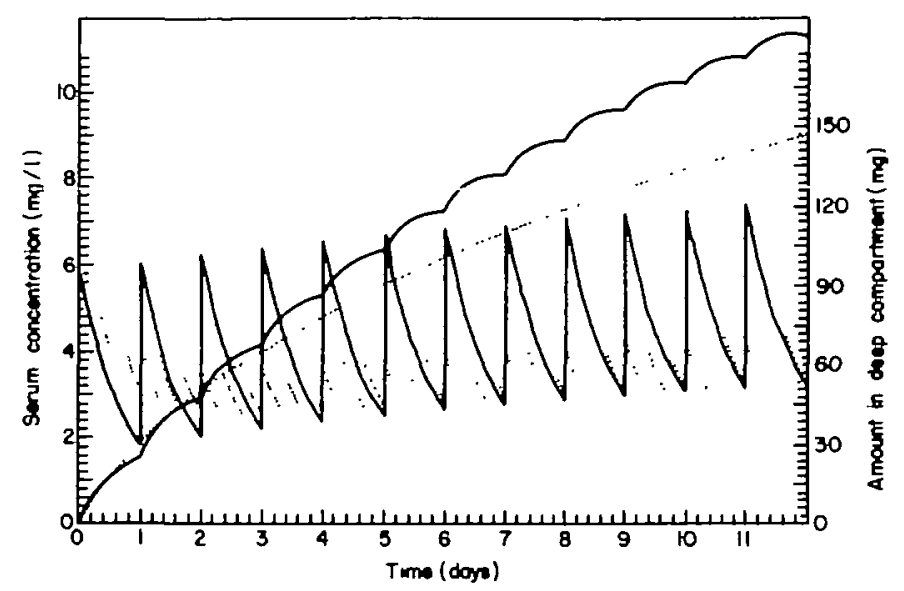

Figure 1. Computer simulation of 2 dosing regimens for tobramycin resulting in identical trough serum concentrations, but significantly different accumulation in the deep tissue compartment. Pharmacokinetic parameters reported by Schentag et al (1978), were used assuming a creatinine clearance of $15 \mathrm{~mL} / \mathrm{min}$. $\ldots \ldots \ldots 20 \mathrm{mg} 8$ hourly, $-72 \mathrm{mg}$ every $24 \mathrm{~h}$.

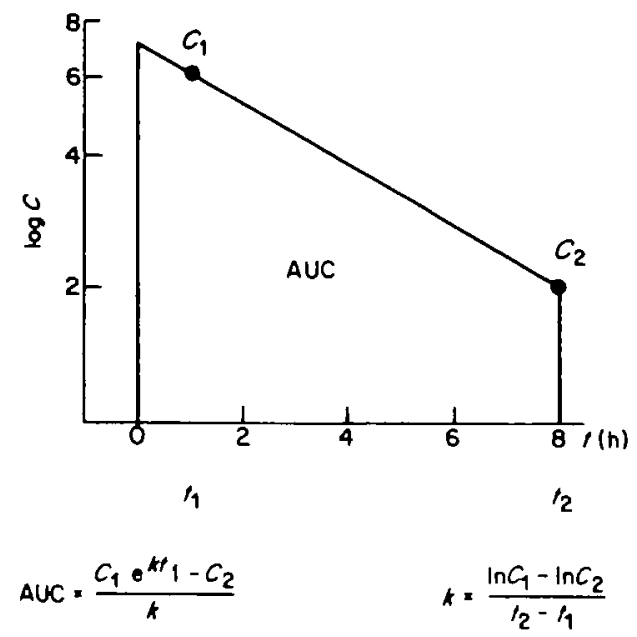

Figure 2. Estimation of the area under the serum concentration curve (AUC) during a dosing interval from 2 serum concentration measurements. $C_{1}=$ concentration $1 \mathrm{~h}$ after the dose, $C_{2}=$ concentration immediately before the next dose, $k=$ elimination rate constant, $t=$ time of blood sample.

available techniques the following four types appear suitable for routine monitoring of aminoglycoside treatment: (A) microbiological assays, (B) radioenzymatic assays (REA), (C) radioimmunoassays (RIA), and (D) enzyme immunoassays.

Each of these methods has its advantages and problems, which should be carefully considered in the selection of the most convenient solution for a particular laboratory.

The agar-diffusion method has a reasonable degree of accuracy, is easy to perform and is inexpensive. However, microbiological measurements are influenced by the presence of other antibiotics, require about $5-18 \mathrm{~h}$ to give the results, and their reproducibility is not as good as that of the newer techniques. 
Radioenzymatic assays are highly specific, sensitive and less time consuming than the bioassays (Holmes \& Sanford, 1974; Smith et al., 1974). A strictly linear standard curve allows accurate measurements over a wide range of concentrations. We found these assays very reliable for the determination of serum and urinary levels of gentamicin, tobramycin, amikacin, netilmicin and sissomicin. The main problem is the production of qualitatively acceptable adenylating and acetylating enzymes. Special equipment and trained personnel are essential.

Radioimmunoassays are most sensitive and highly specific. Various kits are now commercially available for gentamicin, tobramycin, netilmicin and amikacin. A disadvantage of this method is a need for a well-equipped laboratory and the costs of test material. On the whole, radioenzymic and radioimmunoassays are equally suitable for clinical use, and their comparisons show excellent correlations (Watson \& Wenk, 1978; Minishew, Holmes \& Baxter, 1975). More recently, the enzyme multiplied immunoassay technique (EMIT) has also been developed for gentamicin and tobramycin. Instead of radioactive markers an enzyme-antigen complex, specific antibody and an enzyme-substrate are added to the test serum; aminoglycoside concentrations are indicated by a change in light-absorbance that can be measured by a spectrophotometer. Studies in our laboratory (Wenk et al., 1980) and by others (Phaneuf, Francke \& New, 1980; Oeltgen, Hamann \& Blouin, 1981; Francke et al., 1981) revealed a good correlation between results obtained by radioenzymatic or radioimmunoassays and this new technique. By a simple modification we could also use the gentamicin EMIT kit for measuring netilmicin concentrations. The main interest of enzyme-immunoassay is its rapidity and simplicity. An adaptation to semi-automated or automated enzyme analyzers seems to be possible, and so specially trained personnel is not required. However, the costs of EMIT reagents are high, a factor that could limit widespread use.

\section{When should aminoglycoside levels be monitored?}

In view of the practical problems with aminoglycoside dosage and the availability of reliable assay techniques, monitoring of serum concentrations can be recommended to improve effectivity and reduce toxicity. Measurements are indicated in the following situations:

(1) Severe Gram-negative infections in patients with normal renal function in order to ensure bactericidal antibiotic levels. Post-distribution levels (peak) should be determined $\mathrm{l}$ or $2 \mathrm{~h}$ after intravenous or intramuscular administration, respectively. Additional blood samples are needed only in cases of prolonged aminoglycoside treatment or if a tendency to rising creatinine values is seen.

No monitoring is required in patients treated for uncomplicated urinary infection, in whom the dosage interval can often be extended to $24 \mathrm{~h}$ or even longer.

(2) In patients with slight to moderate renal impairment, both peak and trough levels should be obtained to control the adequacy of the dosing regimen. Trough levels repeated every 5-7 days will allow early recognition of abnormal drug accumulation.

(3) In advanced renal failure $\left(\mathrm{Cl}_{\mathrm{cr}}<15 \mathrm{ml} / \mathrm{min}\right)$ repeated serum level measurements are always indicated to avoid toxic concentrations, but at the same 
time to maintain therapeutically effective peak values. Especially in cases with rapidly changing clinical condition, as often seen in septicaemia, close monitoring with repeated blood sampling is necessary.

(4) Aminoglycoside treatment in neonates and small children should probably also be included in this list.

In conclusion, the monitoring of serum levels makes the clinical use of aminoglycosides easier, but this possibility should not lead to a more generous prescription of these antibiotics. Even close surveillance and adaptation of dosage will not eliminate the risk of toxicity. Not only the daily dose, but also the duration of treatment should be limited.

\section{References}

Barza, M. \& Lauermann, M. (1978). Why monitor serum levels of gentamicin? Clinical Pharmacokinetics 3, 202-15.

Barza, M., Lauermann, M. W., Tally, F. P. \& Gorbach, S. L. (1980). Prospective, randomized trial of netilmicin and amikacin with emphasis on eighth-nerve toxicity. Antimicrobial Agents and Chemotherapy 17, 707-14.

Black, R. E., Lau, W. K., Weinstein, R. J., Young, L. S., \& Hewitt W. L. (1976). Ototoxicity of amikacin. Antimicrobial Agents and Chemotherapy 9, 956-61.

Bock, B. V., Edelstein, P. H. \& Meyer, R. D. (1980). Prospective comparative study of efficacy and toxicity of netilmicin and amikacin. Antimicrobial Agents and Chemotherapy 17, 217-25.

Dahlgren, J. G., Anderson, E. T. \& Hewitt, W. L. (1975). Gentamicin blood levels: A guide to nephrotoxicity. Antimicrobial Agents and Chemotherapy 8, 58-62.

Follath F., Spring P., Wenk M., Benet L. Z. \& Dettli L. (1978). Comparative pharmacokinetics of sissomicin and netilmicin in healthy volunteers. In Current Chemotherapy, Vol. Il, pp. 979-980, American Society for Microbiology, Washington D.C.

Francke, E. L., Srinivasan, S., Labthavikul, P. \& Neu, H. C. (1981). Rapid, reproducible enzyme immunoassay for tobramycin. Journal of Clinical Microbiology 93-6.

Gailiunas, P., Dominguez-Moreno, M., Lazarus, J. M., Lowrie, E. G., Gottlieb, M. N. \& Merrill, J. P. (1978). Vestibular toxicity of gentamicin: Incidence in patients receiving long-term hemodialysis therapy. Archives of Internal Medicine 138, 1621-4.

Holmes, R. K. \& Sanford, J. P. (1974). Enzymatic assays for gentamicin and related aminoglycoside antibiotics. Journal of Infectious Diseases 129, 519-27.

Hull, J. H. \& Sarubbi, F. A. (1976). Gentamicin serum concentrations: Pharmacokinetic predictions. Annals of Internal Medicine 85, 183-9.

Mawer, G. E., Ahmad, R., Dobbs, S. M. \& McGough, J. G. (1974). Prescribing aids for gentamicin. British Journal of Clinical Pharmacology I, 45-50.

Minishew, B. H., Holmes, R. K., \& Baxter, C. R. (1975). Comparison of a radioimmunoassay with an enzymatic assay for gentamicin. Antimicrobial Agents and Chemotherapy 7 , 107-9.

Oeltgen, P. R., Hamann, S. R. \& Blouin, R. A. (1980). Comparison of gentamicin assays. Therapeutic Drug Monitoring 2, 423-5.

Phaneuf, D., Francke, E. \& Neu, H. C. (1980). Rapid, reproducible enzyme immunoassay for gentamicin. Journal of Clinical Microbiology II, 266-9.

Sarubbi, F. A. \& Hull, J. H. (1978). Amikacin serum concentrations: Prediction of levels and dosage guidelines. Annals of Internal Medicine 89, 612-18.

Schentag, J. J., Jusko, W. J., Vance, J. W., Cumbo, T. J., Abrutyn, E., de Lattre, M. \& Gerbracht, L. (1977). Gentamicin disposition and tissue accumulation on multiple dosing. Journal of Pharmacokinetics and Biopharmacology 5, 559-77.

Schentag, J. J., Cumbo, T. J., Jusko, W. J. \& Plaut, M. E. (1978). Gentamicin tissue accumulation and nephrotoxic reactions. Journal of the American Medical Association 240, 2067-9. 
Schentag, J. J., Lazezkay, G., Cumbo, T. J., Plaut, M. E. \& Jusko, W. J. (1978). Accumulation pharmacokinetics of tobramycin. Antimicrobial Agents and Chemotherapy 13, 649-56.

Smith, A. L., Waitz, J. A., Smith, D. H., Oden, E. M. \& Emerson, B. S. (1974). Comparison of enzymatic and microbiological gentamicin assays. Antimicrobial Agents and Chemotherapy 6, 316-19.

Smith, C. R., Maxwell, R. R., Edwards, C. Q., Rogers, J. F. \& Lietman P. S. (1978). Nephrotoxicity induced by gentamicin and amikacin. Johns Hopkins Medical Journal, 142, 85-90.

Smith, C. R., Lipsky, J. J., Laskin, O. L., Hellmann, D. B., Mellits, E. D., Longstreth, J. \& Lietman, P. S. (1980). Double-blind comparison of the nephrotoxicity and auditory toxicity of genta micin and tobramycin. New England Journal of Medicine 302, 1 106-9.

Watson, R. A. A. \& Wenk, M. (1978). New tracers in netilmicin and sissomicin radioimmunoassay. In Current Chemotherapy, Vol. II, pp. 906-907. American Society of Microbiology, Washington D.C.

Wenk, M., Spring, P., Vozeh, S. \& Follath, F. (1979). Multicompartment pharmacokinetics of netilmicin. European Journal of Clinical Pharmacology 16, 331-4.

Wenk, M., Vozeh, S., Spring, P. \& Follath, F. (1980). Multicompartment pharmacokinetics of amikacin. In Current Chemotherapy and Infections Disease, American Society of Microbiology Washington D.C.

Wenk, M. \& Follath F. (1980). Enzyme immunoassay for gentamicin in urine and renal tissue. In World Conference on Clinical Pharmacology and Therapeutics (Turner, P. \& Padgham, C., Eds). London. 